\title{
ANALISE DA RESINA POLIURETANA À BASE DE ÓLEO DE MAMONA COMO REVESTIMENTO EM MADEIRAS SUBMETIDAS À TRAÇÃO
}

\section{A NALYSIS OF POLYURETHANE RESIN BASED ON MAMONE OIL AS A COATING ON WOODS SUBMITTED TO TRACTION}

\author{
Jardel Victor Raminelli ${ }^{1}$; João Paulo Matiuso Moçoํㅜ ${ }^{1}$ Larissa Queiroz \\ Minilloº; Bruna Bessa Rocha Yano ${ }^{2}$ \\ ${ }^{1}$ Discentes da Universidade do Oeste Paulista. \\ e-mail: jvraminelli@hotmail.com; joaopaulo_matiuso@hotmail.com; \\ ${ }^{2}$ Docente da Universidade do Oeste Paulista. \\ larissaminillo@gmail.com; bessarochaifsp@gmail.com
}

RESUMO - No mundo todo é antigo o interesse por substituir a madeira nativa por madeira de reflorestamento de crescimento rápido, visando maiores quantidades de material em menor tempo sem perdas em suas propriedades resistivas. Esta pesquisa consiste na comparação do comportamento de peças estruturais in natura com peças estruturais tratadas com resina poliuretana, à base de mamona, em relação à resistência à tração e a flexão, igualmente serão feitos testes para verificar a taxa de absorção e inchamento da madeira após o tratamento com a resina. $O$ tratamento dado as peças estruturais visam melhorar o comportamento mecânico das mesmas. A resina poliuretana bicomponente à base óleo de mamona, fabricada pela empresa Imperveg, foi utilizada no tratamento das peças. Foram realizadas avaliações segundo a NBR7190 (1997) visando caracterizar as propriedades físicas e mecânicas das peças de madeira e os resultados obtidos foram submetidos à análise estatística pelos métodos Anova e Regressão Linear.

Palavras-chave: Resina poliuretana à base de Óleo de Mamona, madeira engenheirada, tração.

Recebido em: 02/08/2018

Revisado em: 27/02/2019

Aprovado em: 26/03/2019
ABSTRACT - The interest in replacing native wood with fast-growing reforestation wood has been long overdue, aiming at larger quantities of material in less time with no loss in its resistive properties. This research consists of comparing the behavior of structural parts in natura with structural parts treated with castor-based polyurethane resin in relation to tensile and flexural strength. Tests will also be carried out to verify the rate of absorption and swelling of the wood after treatment with the resin. The treatment given to the structural parts aims to improve the mechanical behavior of the same. The two-component polyurethane resin based on castor oil, manufactured by Imperveg, was used in the treatment of parts. Evaluations were carried out according to NBR7190 (1997) to characterize the physical and mechanical properties of the pieces of wood and the results were submitted to statistical analysis by the Anova and Linear Regression methods.

Keywords: Polyurethane resin based on castor oil, engineered wood, traction. 


\section{INTRODUÇÃO}

A humanidade está sempre em busca de inovações tecnológicas, sobretudo no campo de materiais. Sendo assim, a madeira, utilizada desde os primórdios, detém diversas propriedades que a tornam muito interessantes em comparação com outros materiais. Um dos pontos que destacam a madeira em relação aos outros materiais é a viabilidade de produção sustentável em florestas plantadas, tornando-a renovável e abundante e também sua variedade de espécies.

$\mathrm{Na}$ construção civil, as indústrias de aço e concreto são em sua maioria mais competitivas e de maior influência nos setores políticos e econômicos, sendo assim, possuem diversas pesquisas relacionadas, propiciando a execução de estudos com maior qualidade técnica.

É de conhecimento comum que há um paradigma com relação a resistência e durabilidade da madeira. Principalmente no Brasil que, por questão cultural, relaciona a madeira à residências de baixa renda. Mas, em outros lugares do mundo, como Estados Unidos e União Europeia, é utilizada e larga escala por suas propriedades de resistência e conforto térmico.

As florestas plantadas de Eucalipto e Pinus chegam a 6,5 milhões de hectares, colocando o Brasil em posição de destaque mundial no setor. Segundo ABRAF (2011), o setor de papel e celulose recebe $36 \%$ da produção madeireira nacional, enquanto $15 \%$ vão para madeira serrada, $11 \%$ para siderurgia e carvão vegetal, $12 \%$ para painéis e compensados, e $26 \%$ para lenhas e outras aplicações.

O melhoramento da capacidade resistiva da madeira pode ser conquistado com a laminação e protensão da madeira. Os tratamentos contra fungos e insetos são conhecidos pela redução da capacidade resistiva da madeira, e a pintura com verniz, por sua vez é conhecida pela impermeabilização e proteção da madeira.
O presente trabalho busca o aumento da resistência mecânica à tração da madeira, resistência à flexão e sua impermeabilização para uso como peças estruturais, utilizando para tal o processo de pintura com resina poliuretana à base de óleo de mamona, material natural já conhecido por agregar resistência à madeira aglomerada.

\section{REVISÃO DA LITERATURA}

\subsection{Madeiras provenientes de coníferas}

Coníferas ou softwoods caracterizamse, principalmente, por possuir folhas afiladas ou em forma de espinho e os seus frutos não possuem casca, estando às sementes expostas e colocadas em volta de um eixo. No Brasil, a conífera nativa mais conhecida é o pinheiro-do-paraná cujo nome científico é Araucaria angustifolia. Outra conífera fornecedora de madeira é uma espécie exótica (nativa de outro país, mas cultivada por aqui) que é o pinus, dos pinus o mais comum no Brasil é o Pinus elliotti (Souza \& Coradin, 2013).

Os pinus são madeiras de densidade menor, fator importante a ressaltar pois a densidade, bem como o teor de umidade da madeira interferem na pintura e colagem da madeira, interferindo também em sua resistência final.

\subsection{Densidade e umidade da madeira}

Considerando uma madeira com uma densidade relativamente baixa, pode-se deduzir que esta possui uma maior porosidade, uma vez que a tem relação inversa à densidade. (KOLLMANN e CÔTÉ apud DIAS, 2005).

Entre os componentes que constituem a madeira, temos a lignina, celulose, poliose, os extrativos e alguns minerais. Os extrativos são os componentes que causam uma certa resistência quando presente na superfície, em termos de contato resina-madeira, ou seja, prejudica a aderência entre a resina e a madeira. (Tsoumis, 1991). 
Segundo LOGSDON et al. (2000) há muito tempo sabe-se que a resistência da madeira varia com seu teor de umidade. Com o aumento do teor de umidade da madeira observa-se uma diminuição em sua resistência.

\subsection{Resina Poliuretana a base de óleo de mamona}

Atualmente, vê-se uma preocupação no que diz respeito a sustentabilidade, onde há uma procura em materiais biodegradáveis, que não agridam o meio ambiente e que sejam derivadas de uma matéria orgânica. (Araújo, 1992)

O óleo de mamona ou também chamado de óleo rícino, é extraído de uma planta bastante conhecida e abundante no Brasil: a Mamona (Ricinus Communis), da família Euforbíces, com base nesse óleo é possível desenvolver pré-polimeros e polióis com propriedades distintas que, quando combinadas, formam o poliuretano. (Dias, 2005).

Jocelen Masson (2017) se refere ao uso de resinas em revestimentos de pisos como as mais resistentes, versáteis e duráveis em relação aos demais sistemas existentes. Dentre os principais tipos de resinas para revestimento temos duas que mais se destacam, epóxis e os poliuretanos.

\subsection{Madeira laminada colada (MLC)}

A madeira laminada colada (MLC), é uma peça formada a partir de lâminas de madeira unidas por um adesivo para uso estrutural ou cola sintética, surgiu há mais de 100 anos na Alemanha com o intuito de melhoramento e reaproveitamento da madeira. Ao longo dos anos teve sua utilização multiplicada para todos os tipos de estrutura, desde móveis e residências à pontes e estádios. Seu uso garante sustentabilidade as florestas e ao meio ambiente.

A MLC tem seus usos mais frequentes em estruturas de cobertura, elementos estruturais principais para pontes, torres de transmissão, edifícios, embarcações, entre outros. Isso se deve ao fato de adaptar-se a uma significativa variedade de formas e apresentar alta resistência a solicitações mecânicas, em função de seu peso próprio relativamente baixo (ZANGIÁCOMO; LAHR, 2007). Como uma das vantagens, permite a redução dos defeitos observados em peças de madeira maciça com grandes dimensões.

Calil (2016) aponta que durante o processo de fabricação o consumo de energia da MLC chega a ser de 5 a 24 vezes menor que alguns materiais como $o$ aço e o concreto, e sua obtenção vem por uma fonte renovável. Outra vantagem é a sua resistência a agentes químicos, baixa necessidade de manutenção e menor tempo de canteiro de obra, que entretanto, refletem em seu custo elevado. Isso deve-se ao fato das lamelas (partes da madeira em formato de lâminas), estarem dispostas paralelamente entre si, através da técnica de laminação e unidas por algum tipo de colagem.

\section{MATERIAIS E MÉTODOS}

Os procedimentos experimentais seguiram a NBR7190 - Projeto de estruturas de madeira (1997) com o intuito de se verificar as propriedades físicas e mecânicas da madeira.

\subsection{Resistência à tração}

Durante os ensaios foi analisada a espécie Pinus (Pinus Elliotti) da qual foram extraídos 10 corpos de prova nas dimensões exigidas pela NBR 7190 (1997) conforme esquema da figura 1. Em primeiro teste, os corpos de prova receberam apenas pintura com resina poliuretana à base de óleo de mamona, cuja fabricação pertence à Imperveg LTDA, de Aguaí, São Paulo. 
Figura 1. Corpos de prova para ensaios de tração paralela as fibras
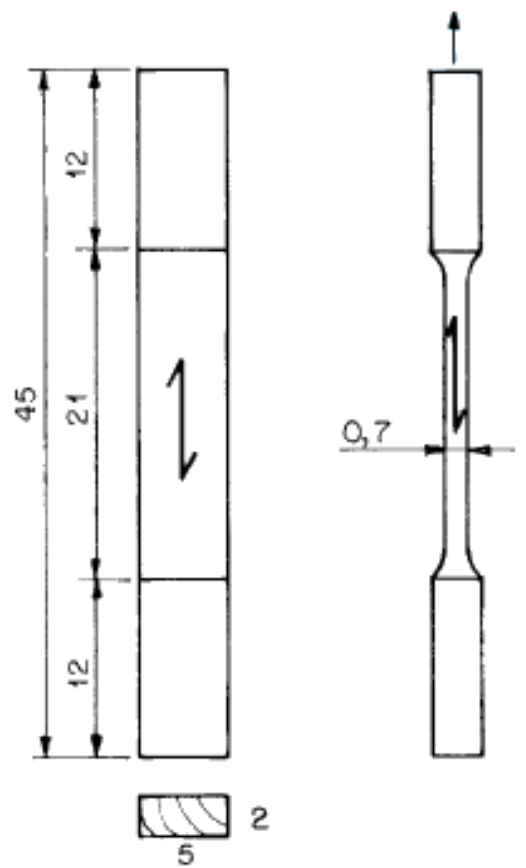

Fonte: NBR 7190. Projeto de estruturas de madeira

Foram confeccionados 3 corpos de prova extra para a determinação da umidade em estufa à $100^{\circ} \mathrm{C}$ por $24 \mathrm{~h}$ conforme NBR 7190 (1997), de tal forma que a umidade possa ser determinada pela equação 1 .

$U(\%)=\frac{m i-m s}{m s} \times 100$

Onde:

$\mathrm{U}$ : umidade, expressa em porcentagem.

ms: massa inicial da madeira, expressa em gramas.

mi: massa final da madeira, expressa em gramas.

Para a aplicação da resina PU a base de óleo de mamona como pintura da peça foi utilizada a proporção $1: 1$, de acordo com suas especificações do fabricante

Os corpos de prova foram divididos em grupo controle, sem pintura, e grupo PU, com pintura de resina poliuretana a base de óleo de mamona.

Após esse processo, os corpos de prova secaram por 72 horas em temperatura ambiente, por volta de $21^{\circ}$, para que fossem rompidos.
Figura 2. Ensaio a tração

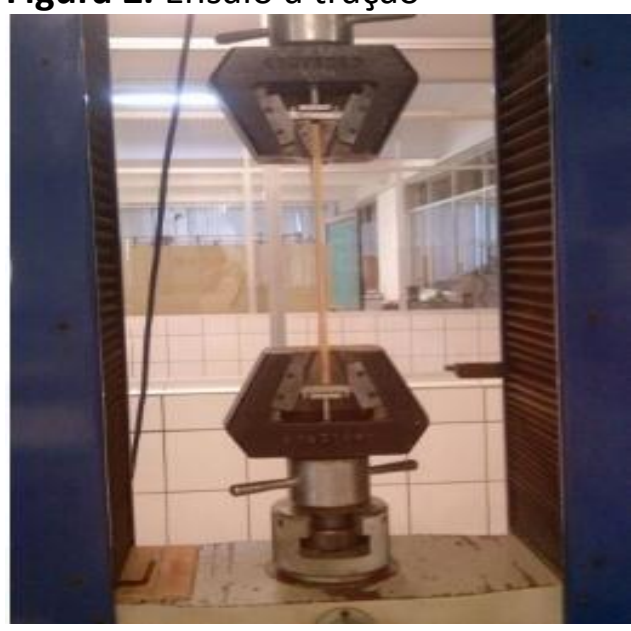

Fonte: Autores

O ensaio a tração foi realizado utilizando a prensa hidráulica universal Pavitest, em que o resultado obtidos com a unidade de medida $\mathrm{kgf} / \mathrm{cm}^{2}$, por meio de um gráfico era possível acompanhar os dados da carga de tração versus tempo.

\subsection{Ensaio de Flexão}

Esse experimento consiste no rompimento das fibras da madeira (Pinus) dispostas paralelamente com o auxílio da prensa universal provida de um cutelo e dois apoios que causam efeito de flexão normal simples.

Os resultados são obtidos em toneladas, de tal forma que devem ser convertidos para tensão normal de flexão pela equação 2.

$\sigma=\frac{M}{I} \times y$

Onde

$\sigma:$ Tensão de flexão normal

M: momento máximo causado pela carga do cutelo em toneladas

I: Inercia da seção transversal da peça y: Distância entre a linha neutra e o ponto de máxima tensão da peça

Os corpos de prova foram padronizados, com forma prismática de seção transversal quadrada de $115,0 \mathrm{~cm}$ na direção paralela das fibras e $5,0 \mathrm{~cm}$ de lado e $2 \mathrm{~cm}$ de altura, conforme visto na figura 3 . 
Estas medidas obedecem as medidas dispostas na NBR 7190 (1997), determinadas pela equação 3 .

$$
21 \times h=d
$$

Sendo

h: altura da seção transversal da peça d: distância entre apoios

Figura 3. Dimensões do corpo de prova ensaio de flexão

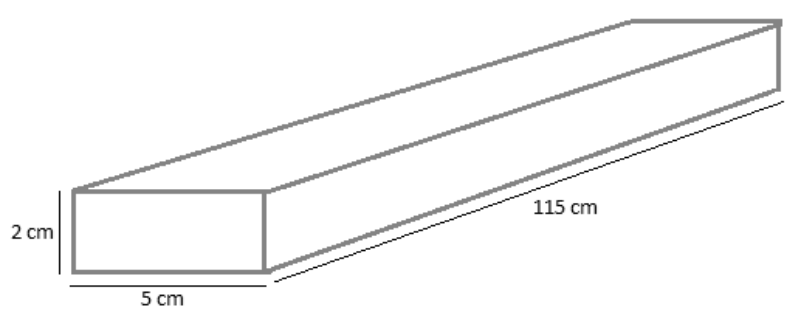

Fonte: Autores

Os corpos de prova assim fabricados foram nomeados grupo controle, e os corpos de prova do grupo PU, desta vez receberam resina PU de mamona entre 2 laminas, cortadas com $1 \mathrm{~cm}$ de $1 \mathrm{~cm}$ de altura, conforme figura 4 .

Figura 4. Representa a união entre os CPs por meio da resina poliuretana.

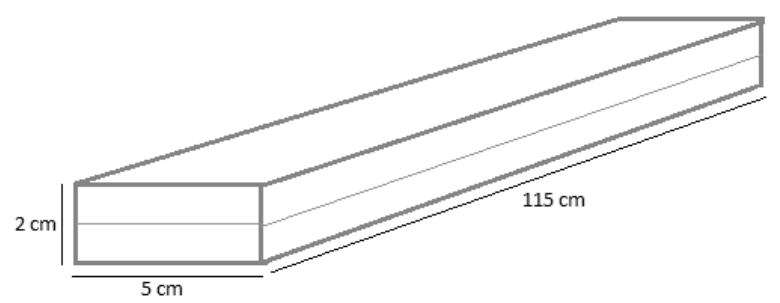

Fonte: Autores

Após fixação das laminas, foi obedecido tempo de secagem de 24 horas em local seco e com temperatura ambiente.

Para o ensaio de ruptura à flexão simples, uma peça com dois apoios articulados de vão livre foi adicionada à prensa (figura 5), com um cutelo responsável por exercer uma força (através de carga concentrada), que deve ser crescente na ordem de $10 \mathrm{MPa} / \mathrm{min}$, segundo a NBR7190 (1997).
Figura 5 - Desenvolvimento do ensaio de flexão pela prensa universal

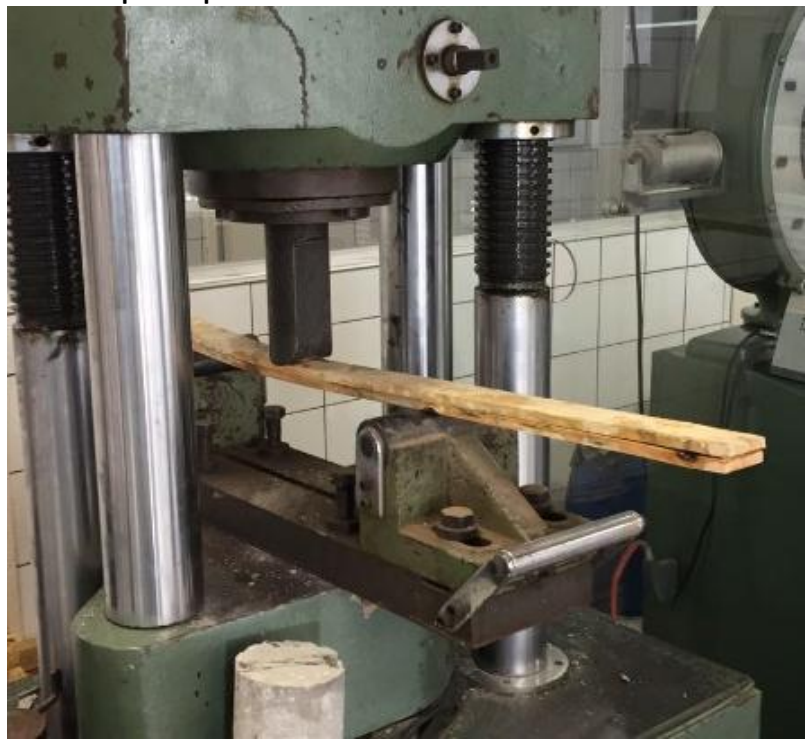

Fonte: Autores

O ponto de excentricidade da peça se localizava exatamente no meio do seu comprimento, ou seja, a $57,5 \mathrm{~cm}$, onde o cutelo era aplicado e encarregado de executar uma força sobre o material, a distância entre apoios foi de $42 \mathrm{~cm}$.

\subsection{Ensaio de Absorção e Inchamento}

Este ensaio é regido pela NBR7190 (1997) e visa determinar o grau de estabilidade dimensional de um lote de madeira através das propriedades de inchamento e inchamento.

A madeira se classifica como um material ortótropo devido as suas diferentes direções axiais correspondentes, radial, tangencial e axial.

A variação de peso (absorção) é determinado utilizando a variação de massa antes $\left(m_{\text {seca }}\right)$ e após período de $24 \mathrm{~h}$ em câmera úmida ( $\left.\mathrm{m}_{\text {saturada }}\right)$.

$$
\Delta M=\frac{m_{\text {saturada }}-m_{\text {seca }}}{m_{\text {seca }}} \times 100
$$

De madeira análoga, a variação volumétrica (inchamento) é calculada em função do peso do corpo de prova saturado e seco.

$\Delta V=\frac{V_{\text {saturada }}-V_{\text {seca }}}{V_{\text {seca }}} \times 100$ 
Os corpos de prova para o ensaio mediam $5 \mathrm{~cm}$ de comprimento por $3 \mathrm{~cm}$ de altura e 2 de largura, conforme figura 6 .

Figura 6. Dimensões dos corpos de prova para ensaio de absorção e inchamento
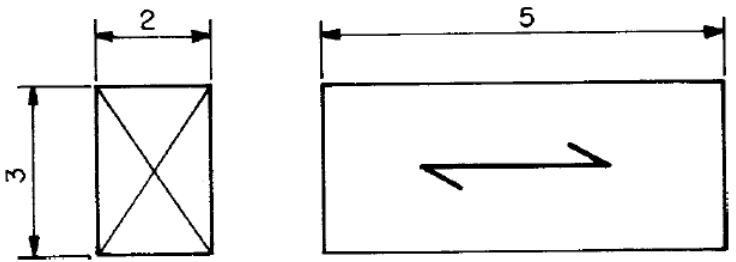

Fonte: NBR 7190 (1997)

Os corpos de prova foram separados em grupo controle, que não receberam pintura de resina PU de mamona, e grupo $\mathrm{PU}$, que receberam a pintura de Resina PU de mamona, contendo 10 corpos de prova cada grupo.

Figura 7. CPs na câmara úmida para absorção da água e inchamento

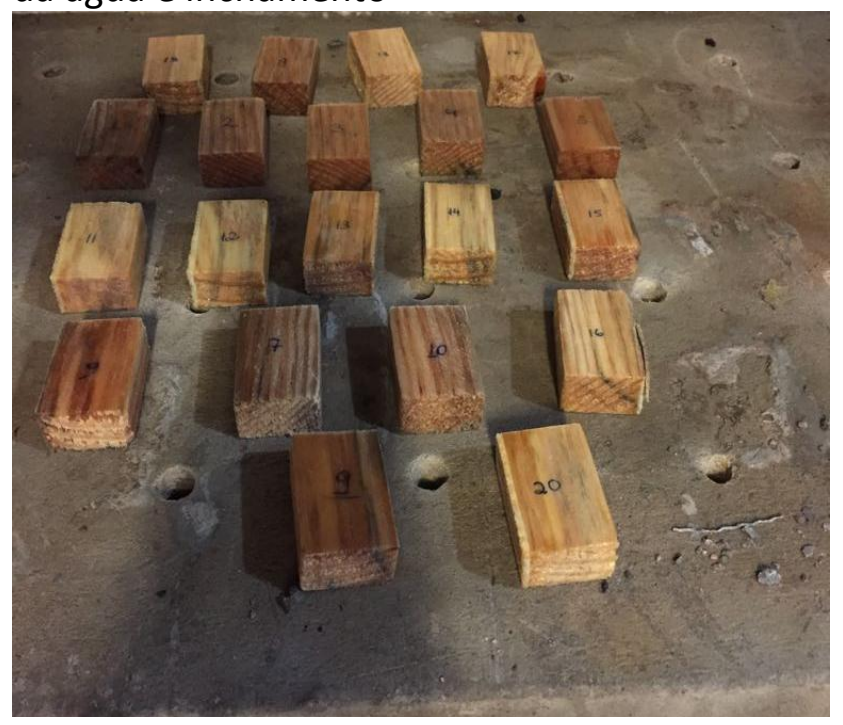

Fonte: Autores

Transcorridas 24 horas em câmara úmida, realizou-se uma nova pesagem e medição.
Figura 8. Corpos de prova do grupo controle após 24 horas em câmera úmida

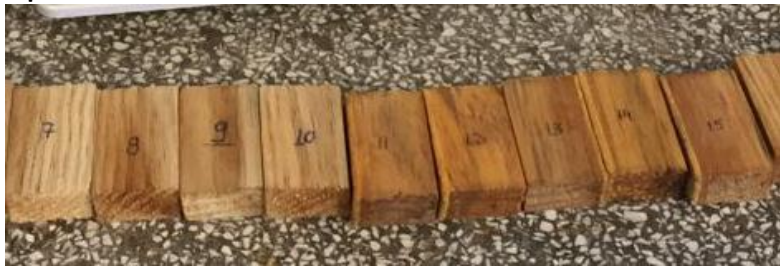

Fonte: Autores

Após pesagem, os corpos de prova secam em estufa a $100^{\circ} \mathrm{C}$ por $24 \mathrm{~h}$ e são novamente pesados e medidos (figura 9).

Figura 9. Corpos de prova em estufa de temperatura controlada à $100 \circ \mathrm{C}$

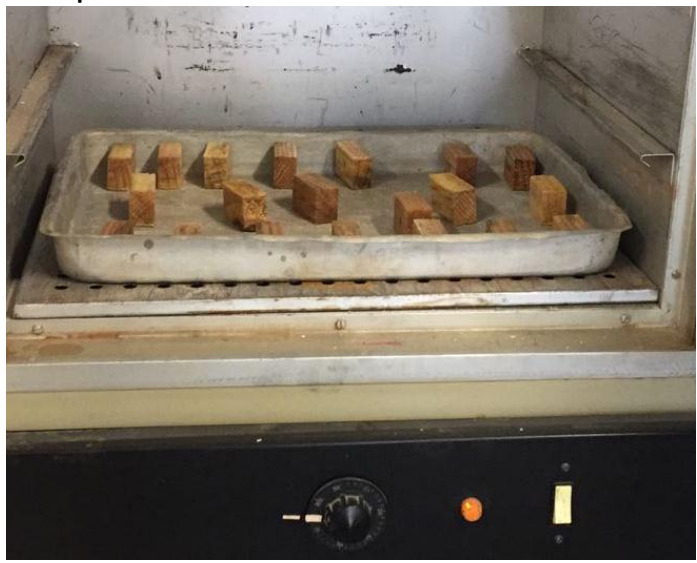

Fonte: Autores

\section{RESULTADOS E DISCUSSÃO DOS RESULTADOS}

\subsection{Tração paralela a fibra}

Os resultados do ensaio de ruptura à tração paralela à fibra da madeira tem comportamento pouco dúctil (figura 10), característica esta que não foi alterada após pintura com resina PU mamona. 
Figura 10. Gráfico de Tração

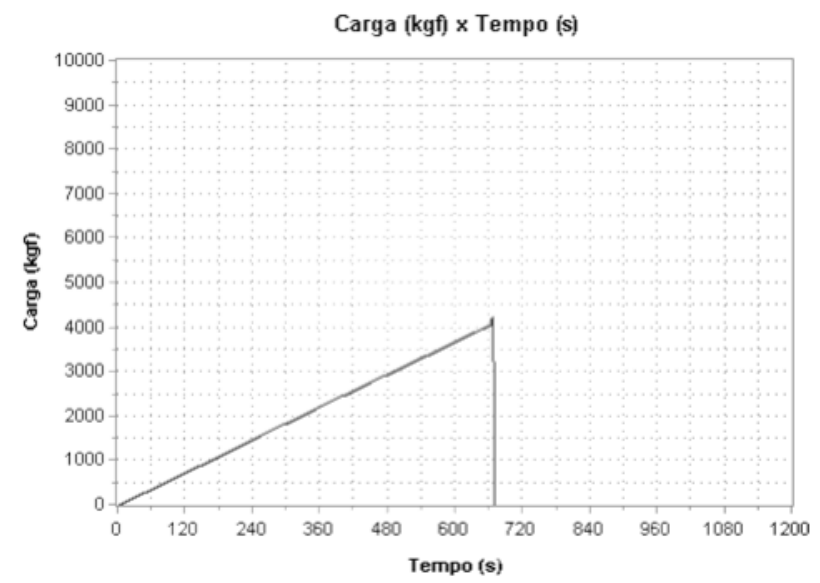

Fonte: Autores

Os resultados da tensão de tração obtidos no ensaio foram organizados na tabela 1, e, analisando-a, verifica-se que o desvio padrão foi relativamente alto devido a alguns fatores inesperados durante o ensaio de tração.

Tabela 1. Resultados de tensão de tração paralela a fibra

\begin{tabular}{|c|c|c|c|}
\hline CP's & $\begin{array}{c}\text { Tensão } \\
\text { (MPa) }\end{array}$ & $\begin{array}{c}\text { Desvio } \\
\text { Padrão } \\
\text { (MPa) }\end{array}$ & $\begin{array}{l}\text { Média } \\
\text { (MPa) }\end{array}$ \\
\hline $\mathrm{C} 1$ & 96,045 & \multirow{5}{*}{27,941} & \multirow{5}{*}{113,03} \\
\hline $\mathrm{C} 2$ & 83,675 & & \\
\hline $\mathrm{C} 3$ & 175,275 & & \\
\hline $\mathrm{C} 4$ & 120,652 & & \\
\hline $\mathrm{C} 5$ & 89,539 & & \\
\hline PU1 & 182,478 & \multirow{6}{*}{77,302} & \multirow{6}{*}{184,80} \\
\hline PU2 & 344,258 & & \\
\hline PU3 & 126,329 & & \\
\hline PU4 & 92,431 & & \\
\hline PU5 & 106,086 & & \\
\hline PU6 & 257,263 & & \\
\hline
\end{tabular}

Fonte: Próprios autores (2018)

Os corpos de prova C3, PU1, PU2 e PU6 apresentaram um resultado incoerente com o padrão devido ao seu alto valor. Esse fato ocorreu por conta de um erro na máquina de ruptura do laboratório que não estava segurando de forma correta os CPS para o ensaio.
Tabela 2. Resultados de densidade e tensão por densidade para tração paralela a fibra

\begin{tabular}{|c|c|c|c|}
\hline CP's & $\begin{array}{c}\text { Densidade } \\
\left(\mathrm{g} / \mathrm{cm}^{3}\right)\end{array}$ & $\begin{array}{l}\text { Tensão por } \\
\text { Densidade } \\
\left(\mathrm{MPa} / \mathrm{g} / \mathrm{cm}^{3}\right)\end{array}$ & $\begin{array}{c}\text { Media da } \\
\text { Densidade } \\
\left(\mathrm{g} / \mathrm{cm}^{3}\right)\end{array}$ \\
\hline C1 & 28,96 & 3,32 & \multirow{5}{*}{34,10} \\
\hline $\mathrm{C} 2$ & 38,80 & 2,16 & \\
\hline $\mathrm{C3}$ & 38,25 & 4,58 & \\
\hline C4 & 36,07 & 3,35 & \\
\hline $\mathrm{C} 5$ & 28,42 & 3,15 & \\
\hline PU1 & 37,16 & 4,91 & \multirow{6}{*}{34,97} \\
\hline PU2 & 42,08 & 8,18 & \\
\hline PU3 & 29,51 & 4,28 & \\
\hline PU4 & 26,78 & 3,45 & \\
\hline PU5 & 32,24 & 3,29 & \\
\hline PU6 & 42,08 & 6,11 & \\
\hline
\end{tabular}

O gráfico de tensão por densidade apresentado pela figura 11 possui alguns pontos fora da linearidade, mas o material utilizado durante o ensaio à tração possui uma tendência de crescimento exponencial de acordo com a densidade.

Figura 11. Regressão linear entre tensão versus densidade

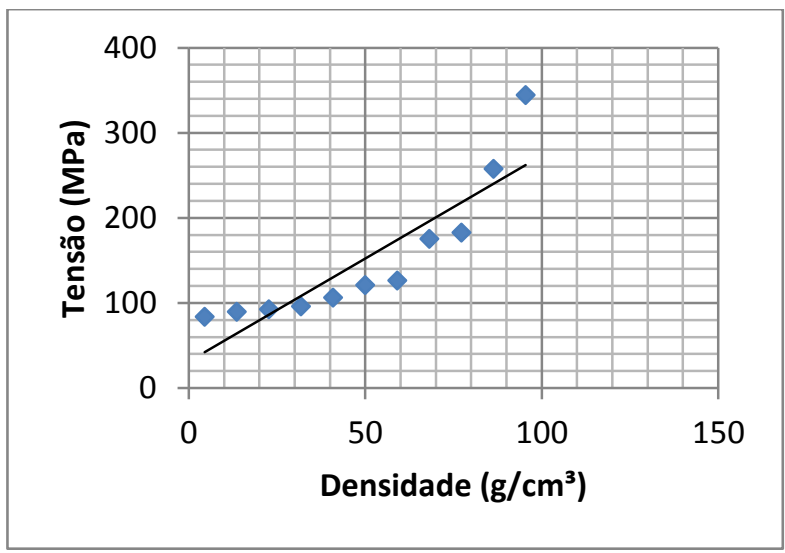

Fonte: Próprios autores (2018)

A análise ANOVA permite analisar se a diferença entre dois ou mais grupos é significante ou é uma consequência fortuita. $O$ valor a ser verificado é o valor $p$, caso ele der inferior a 0,0001, aponta com mais de 99,99\% de confiança que a distinção entre os grupos de analise não foi originado acidentalmente. Sendo assim o valor ideal para que haja distinção entre os dois grupos, é o valor de $p$ menor ou igual a 0,05 (5\%). 
Quadro 1. Resultados da Analise anova entre grupos PU e controle quanto ao Ensaio de Tração

\begin{tabular}{|c|c|}
\hline valor-P & F crítico \\
\hline 0,811807 & 5,117355 \\
\hline
\end{tabular}

Fonte: Próprios autores (2018)

Conforme o Quadro 1, o valor P é de ordem de 0,812, sendo maior que 0,05, demonstrando que não há distinção entre os grupos, ou seja, a utilização da resina poliuretana para tração não foi interferiu nos resultados.

\subsection{Flexão Normal}

Os resultados apresentados nas tabelas 3 e 4 são referentes ao ensaio de flexão entre o grupo controle e o grupo PU, respectivamente.

Tabela 3. Resultados ensaio de flexão para o grupo controle e suas respectivas médias e desvio padrão.

\begin{tabular}{c|c|c|c} 
& $\begin{array}{c}\text { Tensão Flexão } \\
\text { controle (MPa) }\end{array}$ & $\begin{array}{c}\text { Média } \\
\text { (MPa) }\end{array}$ & $\begin{array}{c}\text { Desvio } \\
\text { Padrão } \\
\text { (MPa) }\end{array}$ \\
\hline C1 & 399,22 & & \\
\hline C2 & 354,48 & & \\
\hline C3 & 388,89 & & \\
\hline C4 & 385,45 & & \multirow{2}{*}{377,19} \\
C5 & 385,45 & & \\
\hline C6 & 368,24 & & \\
\hline C7 & 368,24 & & \\
\hline C8 & 364,80 & & \\
\hline C9 & 382,01 & & \\
\hline C10 & 375,13 & &
\end{tabular}

Tabela 4. Resultados ensaio de flexão e suas respectivas médias e desvio padrão, para o grupo PU.

\begin{tabular}{c|c|c|c} 
& $\begin{array}{c}\text { Tensão } \\
\text { Flexão PU } \\
\text { (MPa) }\end{array}$ & $\begin{array}{c}\text { Média } \\
\text { (MPa) }\end{array}$ & $\begin{array}{c}\text { Desvio } \\
\text { Padrão } \\
\text { (MPa) }\end{array}$ \\
\hline PU1 & 406,10 & & \\
\cline { 1 - 1 } PU2 & 382,01 & & \\
\cline { 1 - 1 } PU3 & 364,80 & & \\
\cline { 1 - 1 } PU4 & 392,33 & & \\
\cline { 1 - 1 } PU5 & 409,54 & \multirow{3}{*}{395,78} & \multirow{2}{*}{11,70} \\
\cline { 1 - 1 } PU6 & 399,22 & & \\
\cline { 1 - 1 } PU7 & 392,33 & & \\
\cline { 1 - 1 } PU8 & 406,10 & & \\
\cline { 1 - 1 } PU9 & 416,42 & & \\
\cline { 1 - 1 } PU10 & 388,89 & &
\end{tabular}

O desvio padrão visto para os dois grupos se mostrou baixo, o que indica uniformidade nos CPs e maior confiabilidade nos resultados. Quanto a resistência, nota-se um aumento de 18,6 MPa em média entre grupo PU e grupo $\mathrm{C}$ (controle).

Quadro 2. Resultados da análise Anova entre grupos PU e controle quanto ao Ensaio de Flexão

\begin{tabular}{|c|c|}
\hline valor-P & F crítico \\
\hline 0,009 & 4,414 \\
\hline
\end{tabular}

Fonte: Próprios autores (2018)

Os dados apresentados no quadro 2 indicam o valor $P$ igual a 0,009 , sendo menor que 0,05 . $O$ resultado mostra que o emprego da resina poliuretana nos $\mathrm{CPs}$ resulta em uma diferença significativa entre o grupo $\mathrm{PU}$ e o grupo controle, evidenciando que a utilização da resina para viga laminada colada é válida. 
Figura 12. Gráfico da densidade x resistência à flexão

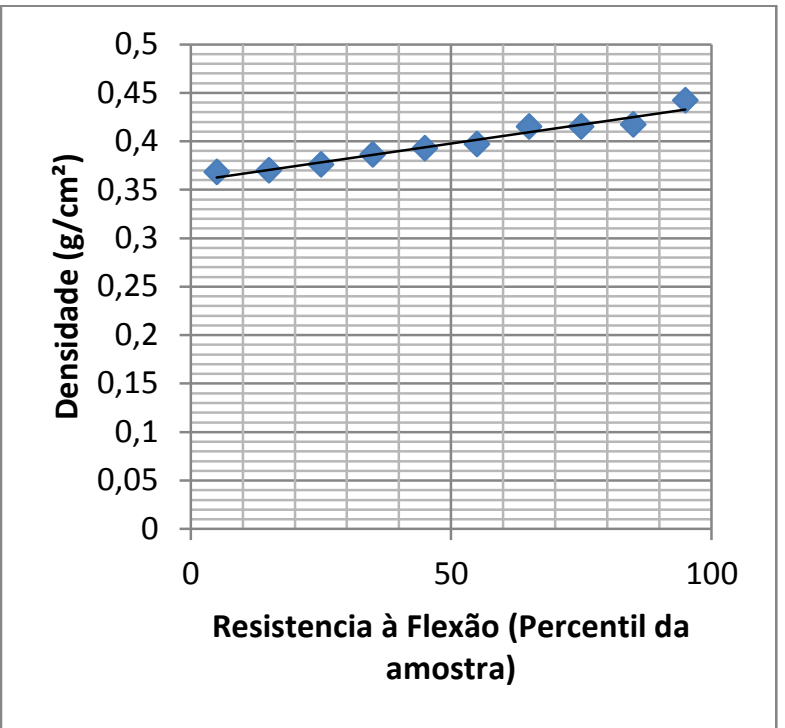

Fonte: Próprios autores (2018)

$\mathrm{Na}$ figura 12 nota-se linearidade entre a densidade e a resistência à flexão.

\subsection{Absorção de água}

Tabela 5.1 Resultados dos grupos em relação ao ganho de umidade após $24 \mathrm{~h}$ em câmara úmida

\begin{tabular}{|c|c|c|c|c|}
\hline & & $\begin{array}{l}\text { Umidade } \\
\text { (\%) }\end{array}$ & $\begin{array}{c}\text { Média } \\
(\%)\end{array}$ & $\begin{array}{c}\text { Desvio } \\
\text { Padrão (\%) }\end{array}$ \\
\hline \multirow{10}{*}{ 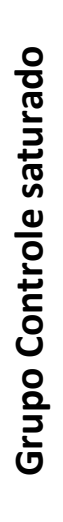 } & 1 & 215,69 & \multirow{10}{*}{190,53} & \multirow{10}{*}{15,41} \\
\hline & 2 & 174,65 & & \\
\hline & 3 & 170,82 & & \\
\hline & 4 & 172,24 & & \\
\hline & 5 & 203,75 & & \\
\hline & 6 & 196,07 & & \\
\hline & 7 & 168,35 & & \\
\hline & 8 & 203,99 & & \\
\hline & 9 & 189,52 & & \\
\hline & 10 & 210,19 & & \\
\hline \multirow{10}{*}{ 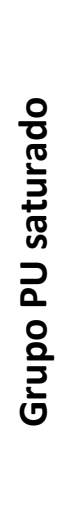 } & 11 & 104,51 & \multirow{10}{*}{99,20} & \multirow{10}{*}{20,90} \\
\hline & 12 & 40,78 & & \\
\hline & 13 & 121,82 & & \\
\hline & 14 & 70,24 & & \\
\hline & 15 & 127,22 & & \\
\hline & 16 & 111,96 & & \\
\hline & 17 & 120,20 & & \\
\hline & 18 & 82,53 & & \\
\hline & 19 & 113,97 & & \\
\hline & 20 & 98,71 & & \\
\hline
\end{tabular}

Observa-se que o ganho médio de umidade dos CP's sem cola foi aproximadamente o dobro em relação ao ganho dos CP's com cola, constatando assim a eficiência da cola no que diz respeito como impermeabilizante.

Quadro 3. Anova: Comparação entre corpos de prova grupo controle e corpos de prova grupo PU

\begin{tabular}{|l|l|}
\hline valor-P & F crítico \\
\hline 0,264154 & 4,413873 \\
\hline
\end{tabular}

Fonte: Próprios autores (2018)

Quadro 4. Anova: Comparação entre corpos de prova saturados grupo controle e corpos de prova saturados grupo PU

\begin{tabular}{|l|l|}
\hline valor- $P$ & F crítico \\
\hline 0,000694 & 4,413873 \\
\hline
\end{tabular}

Fonte: Próprios autores (2018)

\section{CONCLUSÃO}

$\mathrm{Na}$ utilização da resina poliuretana no tratamento de peças de madeira submetidas a esforço de tração com o objetivo de aumentar a resistência, não se obteve uma diferença significativa entre os grupos, porém esses dados não são conclusivos, uma vez que a prensa não era capaz de tracionar os corpos de prova corretamente.

No ensaio de flexão, a resina ofereceu benefícios que acrescentaram no enrijecimento das fibras da madeira. Com base nos dados fornecidos pelo Anova, verificou-se que há uma diferença significativa entre os grupos, em média 0,7 MPa de acréscimo de resistência à flexão com a utilização da resina entre as lâminas. Para estudos posteriores, indica-se analisar a madeira laminada colada com 3 lâminas de madeira.

No que diz respeito ao ensaio de umidade, os corpos de prova sem a aplicação da resina obtiveram uma absorção de água de aproximadamente 2,15 vezes maior do que os corpos impermeabilizados, demonstrando que a resina pode ser usada 
como impermeabilizante. Para trabalhos futuros indica-se a utilização da resina com um maior número de camadas.

\section{REFERÊNCIAS}

ARAUJO, L. C. R. Caraterização física e mecânica de poliuretanas elastoméricas baseados em materiais oleoquímicas. 1992. Dissertação (Mestrado) - Instituto de Física e Química de São Carlos. Universidade de São Paulo, São Carlos, 1992.

ASSOCIAÇÃO BRASILEIRA DE NORMAS TÉCNICAS. Projeto de estruturas de madeira: NBR 7190. Rio de Janeiro: ABNT, 1996.

DIAS, F. M. Aplicação da resina poliuretana à base de mamona na fabricação de painéis de madeira compensada e aglomerada. 2005. Tese (Doutorado). Universidade de São Paulo. Ciência Engenharia dos Materiais. São Carlos, 2005.

LOGSDON, N. B.; CALIL JUNIOR, C.. Influência da umidade nas propriedades de resistência $e$ rigidez da madeira. Cadernos de Engenharia de Estruturas, São Carlos, n. 18, p. 77-107, 2002.

MINILLO, L. Q. Aproveitamento de resíduo das industrias de celulose e sucroalcoleira para produção de painéis aglomerados. 2017. Dissertação (Mestrado) - Universidade Estadual Paulista. Faculdade de Engenharia, Ilha Solteira, 2017.

PHILPOT, T. A. Mecanica dos materiais: um sistema integrado de ensino. 2. ed. Rio de Janeiro: LTC - Livros Técnicos e Científicos,2013.

SANTOS, P. R.. Análise e cálculo de elementos estruturais em concreto armado de um edifício residencial. 2014. Trabalho de Conclusão de Curso (Engenharia Civil) - Universidade Federal de Santa Catarina, Florianópolis, 2014.

\section{MASSON, J.Resinas Epoxídicas na Construção} Civil: estudo de pisos epoxídicos. Trabalho de Conclusão de Curso. Escola de Engenharia da Universidade Presbiteriana MackenzieUPM, São Paulo, Brasi 2017.

PELLIS, F. P. Desempenho estrutural de vigas em madeira laminada colada armada. 2011.
Trabalho de conclusão de curso (bacharelado Engenharia Industrial Madeireira) -Universidade Estadual Paulista "Júlio de Mesquita Filho", Campus Experimental de Itapeva, 2011.

Disponível em:

http://hdl.handle.net/11449/120472.

PETRAUSKI, S. M. F. C. Desenvolvimento de pórticos de madeira laminada colada de eucalipto, utilizando adesivos à base de resorcinol e óleo de mamona. 2012. Tese (Doutorado) - Universidade Federal de Viçosa, 2012.

FIALDINI,R. Modelos de guarda corpo com madeira laminada. (2013)

NAKAMURA, J. Estabilidade dimensional e resistência mecânica determinaram a madeira laminada colada na reforma da Biblioteca Paulo Freire, em Itaipu. Téchne, Edição 208, jul. 2014. 